\title{
ĐÁNH GIÁ HIỆU QUẢ CỦA QUÁ TRÌNH CHUỘI TƠ TẰM BẰNG OZONE SO VỚI PHUOONG PHÁP TRUYỂN THỐNG
}

\author{
TRÀN NGUYỄN TÚ UYÊN ${ }^{1}$, BÙI MAI HƯƠNG ${ }^{2}$, PHAMM THI THẢO ${ }^{3}$ \\ ${ }^{1,3}$ Faculty of Garment and Fashion Design, Industrial University of Ho Chi Minh city, Vietnam \\ ${ }^{2}$ Department of Textile-Garment Engineering, Ho Chi Minh city University of Technology \\ tuuyentk@gmail.com
}

Tóm tắt. Trong nghiên cứu này, ozone được sử dụng để chuội và tẩy trắng vải tơ tằm. Ảnh hưởng của phương pháp này lên một số tính chất cơ lý của vải được đánh giá và so sánh với phương pháp chuội bằng xà phòng và tẩy trắng bằng hydrogen peroxit $\left(\mathrm{H}_{2} \mathrm{O}_{2}\right)$ truyền thống. Kết quả nghiên cứu khi xử lý ở môi trường khô trong 10,20 và 30 phút đối với mẫu ngấm ép $50 \%$ dung dịch $\mathrm{HCl} \mathrm{pH} 4$ cho thấy phương pháp xử lý bằng ozone đã giúp loại bỏ keo sericin trong tơ thô, thành phần fibroin không bị ảnh hưởng, độ giãn đứt dọc tăng, độ bền đứt và khối lượng giảm, thời gian xử lý càng tăng thì giá trị các tính chất càng giảm. Đồng thời, mẫu vải đã xử lý đáp ứng được yêu cầu về độ bền màu sau khi ứng dụng làm khăn tay trang trí bằng phương pháp thủ công, cho thấy tính khả thi của sản phẩm trong may mặc và thời trang. Mặt khác, phương pháp ozone chỉ cần sử dụng một lượng xà phòng bằng khoảng $40 \%$ so với phương pháp chuội keo bằng xà phòng thông thường với thời gian xử lý ít hơn.

Từ khóa. Ozone, tơ tằm, fibroin, chuội keo, tẩy trắng.

\section{A STUDY ON EFFECTIVENESS OF OZONE TREATMENT AS A GREEN METHOD FOR DEGUMMING AND BLEACHING SILK}

\begin{abstract}
This study investigated the effect of ozone treatment on 100\% raw mulberry silk and its influence on fabric physical properties, the results were compared with traditional degumming method by soap and bleaching by hydrogen peroxide $\left(\mathrm{H}_{2} \mathrm{O}_{2}\right)$ for reference. It was observed that sericin in raw silk was removed and the fibroin was not affected after treatment. The treatment result increase in elongation, decrease in breaking strength and weight under dry treatment condition, wet pick up 50\% of hydrochloric acid $(\mathrm{HCl}) \mathrm{pH} 4$ in 10, 20, and 30 minutes, these properties values decrease with treatment time increase. The hand-painted scarf using treated fabric provide good color fastness that can be used in fashion apparel. Besides, soap used in ozone treatment is $40 \%$ of that in the traditional method in less time treatment.
\end{abstract}

Keywords. Ozone, silk, fibroin, degumming, bleaching.

\section{GIÓ́I THIÊUU}

Tơ tằm thô là sợi protein có nguồn gốc động vật gồm hai thành phần chính là fibroin và sericin chiếm lần lượt khoảng $75 \%$ và $25 \%$ khối lượng tơ. Fibroin trong tơ tằm ở dạng hai sợi dài liên tục song song với nhau và được bao phủ bên ngoài bởi lớp keo sericin và một số tạp chất khác như chất béo và muối. Thành phần fibroin trong tơ tằm gồm một chuỗi polypeptide được cấu tạo bởi 18 amino acid [1], có ngoại quan trơn láng, độ bóng cao, được sử dụng để dệt vải hoặc ứng dụng trong một số lĩnh vực khác. Một trong những khâu quan trọng trong sản xuất vải tơ tằm là "chuội" vải, đây là quá trình xử lý làm sạch, loại bỏ chất keo sericin bên ngoài bằng cách phân cắt các liên kết peptide của sericin, giải phóng 2 sợi fibroin giúp sợi tơ mềm mại, bóng, thoáng, tăng độ giãn,v.v... Có rất nhiều phương pháp chuội keo, phổ biến nhất là các phương pháp chuội keo bằng xà phòng kết hợp với kiềm, chuội keo bằng siêu âm, bằng các chất tẩy rửa tổng hợp và chuội keo dưới áp suất ở nhiệt độ cao [2]. Khâu chuội vải tơ tằm ở Việt Nam hiện nay thường sử dụng quy trình ướt với xà phòng và một số hóa chất khác. Hiện nay trên thế giới đã có một số nghiên cứu về xử lý vải bằng khí ozone nhằm xây dựng quy trình xử lý giảm thiểu tối đa tác hại đến môi trường. Ozone $\left(\mathrm{O}_{3}\right)$ là một chất oxy hóa mạnh, có dạng khí ở điều kiện và áp suất tiêu chuẩn, màu xanh nhạt và có mùi tanh, nó là một dạng thù hình không ổn định của oxy chứa 3 nguyên tử oxy. Ozone bị hóa lỏng ở nhiệt độ $-112{ }^{\circ} \mathrm{C}$, hóa rắn ở $-193{ }^{\circ} \mathrm{C}$, ở hai trạng thái này nó đều có màu xanh thẫm đặc trưng. Nó có tác dụng 
oxy hoá cực mạnh, hơn clo hàng trăm lần nhưng không bền vững nên chỉ có thể sản xuất dùng ngay tại chỗ. Xử lý bằng ozone không tạo ra các hợp chất phụ độc hại nào kèm theo nên từ lâu đã được các nước có nền khoa học phát triển ứng dụng và coi ozone như một chất oxy hóa làm sạch lý tưởng nhất [3]. Ozone đã được phổ biến nhanh chóng trong nhiều lĩnh vực như sát khuẩn, khử độc, khử mùi, khử màu, làm sạch không khí, nước uống, nước thải, bảo quản, chế biến thực phẩm...Trong ngành dệt may nói riêng, ozone được dùng để khử bẩn màu nước thải nhuộm bằng cách tấn công vào các liên kết đôi của thuốc nhuộm, xử lý để tăng tốc độ nhuộm và khả năng hấp thụ màu nhuộm của vải polyester [4]. Với khả năng oxy hóa cao, sử dụng ozone trong tẩy trắng vải đã được nghiên cứu và ứng dụng, kết quả cho thấy trong một thời gian rất ngắn, vải cotton có thể được tẩy trắng [5]. Ngoài ra một số yếu tố ảnh hưởng đến xử lý tẩy trắng cotton bằng ozone như độ ẩm và độ $\mathrm{pH}$ cũng được nghiên cứu và so sánh với phương pháp tẩy trắng thông thường bằng $\mathrm{H}_{2} \mathrm{O}_{2}$, cho thấy khả năng ứng dụng tẩy trắng vật liệu dệt của ozone. Nghiên cứu của Tomiji năm 2004 [9] về xử lý vải tơ tằm bằng ozone cho thấy vải sau xử lý có độ thấm hút nước tăng, độ co sau giặt giảm, tốc độ nhuộm của vải sau xử lý tăng, mặc dù không có sự thay đổi nhiều về bề mặt khi quan sát ảnh SEM nhưng cảm giác sờ tay của vải khô hơn. Xử lý chuội và tẩy trắng vải tơ tằm bằng ozone cũng đã được nghiên cứu bởi D.Sargunamani và cộng sự [10] cho thấy hiệu quả xử lý cao nhất khi mẫu được ngấm ép $50 \%, \mathrm{pH} 4$, thời gian xử lý 30 phút. Kết quả độ bền và giãn đứt của vải giảm, độ ngả vàng cao hơn, hiệu quả loại bỏ sericin thấp hơn so với phương pháp chuội bằng xà phòng. Nghiên cứu của Nurşah Balci và cộng sự [7] khi xử lý tơ tằm bằng ozone và plasma cũng kết luận độ bền của vải giảm, độ ngả vàng tăng khi kéo dài thời gian xử lý. Trong bài báo này, tác giả đã thử nghiệm xử lý chuội và tẩy trắng vải tơ tằm bằng phương pháp ozone trong môi trường khô, đồng thời đánh giá hiệu quả của phương pháp này với phương pháp chuội xà phòng và tẩy trắng vải tơ tằm bằng $\mathrm{H}_{2} \mathrm{O}_{2}$ truyền thống.

\section{THỰC NGHIÊM}

\subsection{Hóa chất và vật liệu}

Vải tơ tằm dâu thô $100 \%$ (chưa chuội keo) khối lượng $56 \mathrm{~g} / \mathrm{m}^{2}$, mật độ dọc 132 sợi $/ \mathrm{cm}$, mật độ ngang 98 sợi/cm, chỉ số sợi dọc $46 \mathrm{D}$, sợi ngang $67 \mathrm{D}$ được sử dụng cho thí nghiệm chuội keo bằng xà phòng và chuội keo bằng khí ozone.

Các hóa chất sử dụng trong thí nghiệm: Xà phòng Marseille (MS), axit acetic $\left(\mathrm{CH}_{3} \mathrm{COOH}\right)$, natri cacbonat $\left(\mathrm{Na}_{2} \mathrm{CO}_{3}\right), \mathrm{H}_{2} \mathrm{O}_{2} 30 \%$, natri silicat $\left(\mathrm{Na}_{2} \mathrm{SiO}_{3}\right)$, natri hydroxit $(\mathrm{NaOH})$, kali hydroxit $(\mathrm{KOH})$, đồng (II) sulfate, nước cất, màu vẽ lụa chuyên dụng trong hội họa và thiết kế thời trang Silk Green label Jacquard.

\subsection{Sơ đồ thực nghiệm và quy trình công nghệ xử lý vải tơ tằm bằng Ozone}

Các bước thực nghiệm được trình bày theo sơ đồ hình 1

Quy trình chuội vái tơ tằm thô bằng xà phòng [6]: Mẫu vải tơ tằm thô được chuội trong dung dịch gồm nước cất, xà phòng $\mathrm{MS}$ tỷ lệ $5 \mathrm{~g} / 1,0,015 \mathrm{~g} \mathrm{Na} \mathrm{CO}_{3}$ ở nhiệt độ $90^{\circ} \mathrm{C}$ trong 60 phút bằng máy nhuộm hồng ngoại, sau đó được giặt sạch bằng nước và sấy bằng máy máy sấy $\mathrm{M} 120-\mathrm{VF}$ ở điều kiện $70^{\circ} \mathrm{C}$ trong 10 phút. Mẫu sau khi được xử lý chuội bằng phương pháp xà phòng sẽ được lưu làm mẫu thử cho thí nghiệm tẩy trắng tơ tằm bằng ozone và bằng $\mathrm{H}_{2} \mathrm{O}_{2}$. 


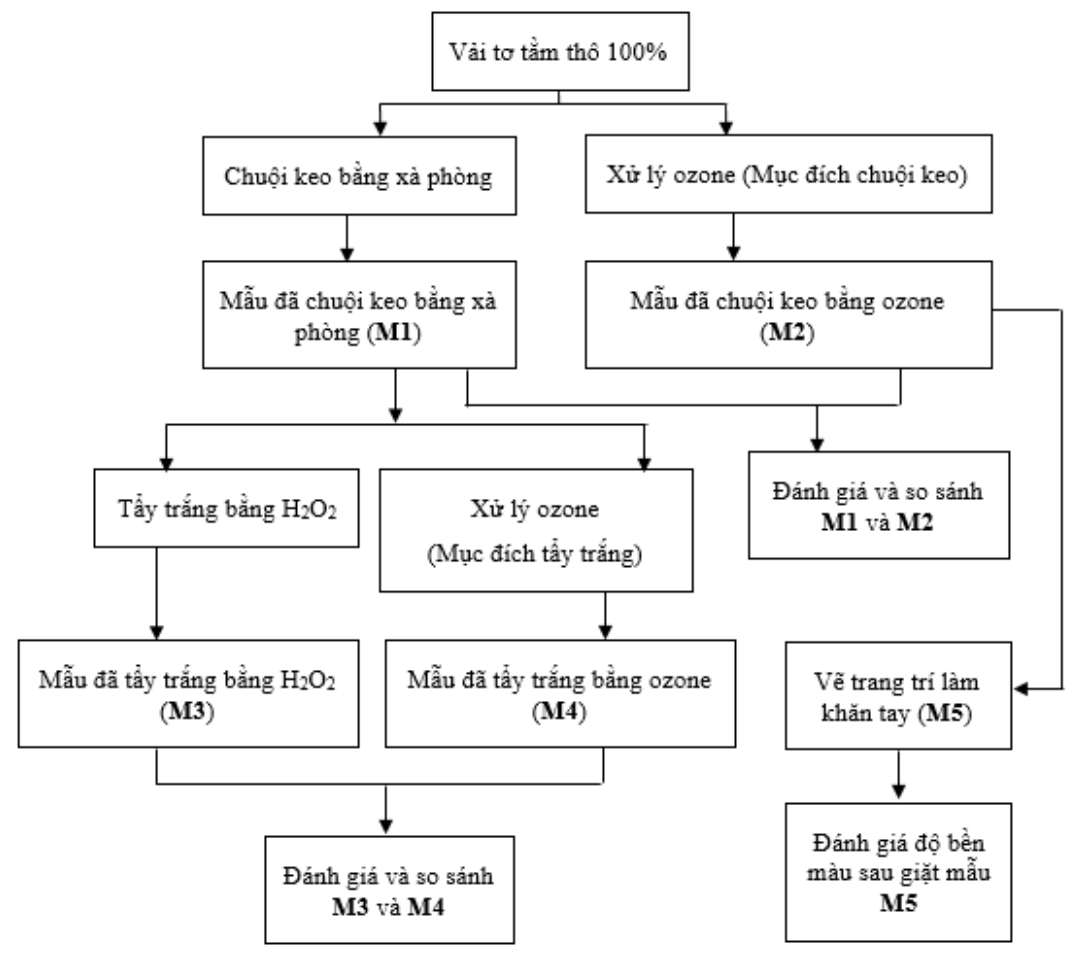

Hình 1. So đồ thực nghiệm

Chuội vải tơ tằm bằng ozone quy trình khô: Mẫu vải tơ tằm thô được ngấm ép $50 \%$ với dung dịch $\mathrm{HCl} \mathrm{pH} 4$ và được xử lý ozone ở nồng độ $60 \mathrm{~g} / \mathrm{m}^{3}$, lưu lượng 2 lít/phút trong 10,20 và 30 phút máy ozone PC57L-16. Các mẫu sau khi xử lý được giặt bằng xà phòng MS tỷ lệ $2 \mathrm{~g} / 1$ ở $85^{\circ} \mathrm{C}$ trong 10 phút, sau đó giặt sạch lại bằng nước, sấy khô mẫu ở $70^{\circ} \mathrm{C}$ trong 10 phút và điều hòa mẫu trong điều kiện tiêu chuẩn.

Tẩy trắng vải tơ tằm bằng $\mathrm{H}_{2} \mathrm{O}_{2}$ : Tẩy trắng mẫu $\mathrm{M} 1$ bằng dung dịch pha từ $20 \mathrm{ml}$ nước cất, $0.4 \mathrm{ml} \mathrm{H}_{2} \mathrm{O}_{2}$, $0.025 \mathrm{~g} \mathrm{Na}_{2} \mathrm{SiO}_{3}$ ở $^{9} 90^{\circ} \mathrm{C}$ trong 60 phút. Giặt sạch bằng nước, sáy khô, điều hòa ở điều kiện tiêu chuẩn.

Tẩy trắng vải to tằm bằng ozone: Mẫu $\mathrm{M} 1$ được ngấm ép $50 \%$ với dung dịch $\mathrm{HCl} \mathrm{pH} 4$ và được xử lý ozone ở nồng độ $60 \mathrm{~g} / \mathrm{m}^{3}$, lưu lượng 2 lít/phút trong 10,20 và 30 phút. Mẫu sau xử lý được giặt sạch bằng nước và sấy khô ở $70^{\circ} \mathrm{C}$ trong 10 phút, điều hòa mẫu trong điều kiện tiêu chuẩn.

Vê khăn lụa tù mẫu đã chuội ozone: Mẫu M2 sau khi điều hòa ở điều kiện chuẩn được vẽ trang trí thủ công bằng màu chuyên vẽ lụa Jacquard green label làm khăn tay thời trang, sản phẩm được đánh giá độ bền màu sau giặt.

\subsection{Thiết bị và phương pháp phân tích}

Phân tích cấu trúc:

Sử dụng kính hiển vi điện tử quét SEM (Scanning Electron Microscope Evo18 Carl Zeiss) để quan sát và đánh giá sự thay đổi cấu trúc ngoại quan của vật liệu trước và sau khi xử lý chuội, thực hiện tại Trung tâm Công nghệ sinh học Tp. Hồ Chí Minh.

Phân tích các mẫu bằng máy quang phổ FT-IR Nicolet 6700 để thu được biểu đồ giải phổ của mẫu trước và sau khi xử lý, giúp nghiên cứu cơ chế phản ứng hóa học của mẫu khi xử lý ozone.

Phân tích tính chất cơ lý

+ Khối lượng của mẫu: Xác định phần trăm thay đổi về khối lượng của mẫu trước và sau khi làm xử lý bằng cân điện tử phân tích có độ chính xác $0,0001 \mathrm{~g}$ tại Phân viện Dệt May Tp. Hồ Chí Minh. Mẫu được điều hòa tối thiểu $24 \mathrm{~h}$ trong phòng điều kiện tiêu chuẩn với độ ẩm $65 \pm 2 \%$ và nhiệt độ $21 \pm 2^{\circ} \mathrm{C}$ trước khi được cân. Phần trăm thay đổi khối lượng được tính theo công thức:

$$
\mathrm{X}=\frac{\mathrm{M}_{1}-\mathrm{M}_{0}}{\mathrm{M}_{0}} \times 100(\%)
$$

$\mathrm{M}_{0}$ : Khối lượng mẫu thử trước xử lý $(\mathrm{g})$

$\mathrm{M}_{1}$ : Khối lượng mẫu thử sau xử lý $(\mathrm{g})$ 
+ Độ bền đứt, độ giãn đứt: Thực hiện trên thiết bị Universal Testing Machine - Titan 4 theo tiêu chuẩn TCVN 7121:2014 tại Phân viện Dệt May Tp. Hồ Chí Minh, áp dụng cho các loại vải dệt thoi, không dệt và vải nỉ.

Phần trăm thay đổi của độ bền kéo đứt $(\mathrm{Y})$ của mẫu trước và sau khi xử lý được tính theo công thức:

$$
\mathrm{Y}(\%)=\frac{\mathrm{B}_{1}-\mathrm{B}_{0}}{\mathrm{~B}_{0}} \times 100(\%)
$$

$\mathrm{B}_{0}$ : Độ bền kéo đứt của mẫu trước xử lý $(\mathrm{N})$

$\mathrm{B}_{1}$ : Độ bền kéo đứt của mẫu sau xử lý $(\mathrm{N})$.

Phẩn trăm thay đổi độ giãn đứt $(\mathrm{E})$ của mẫu trước và sau khi xử lý được tính theo công thức:

$\mathrm{E}_{0}$ : Độ giãn đứt của mẫu trước xử lý (\%)

$$
\mathrm{E}(\%)=\frac{\mathrm{E}_{1}-\mathrm{E}_{0}}{\mathrm{E}_{0}} \times 100(\%)
$$

$\mathrm{E}_{1}$ : Độ giãn đứt của mẫu sau xử lý (\%).

Đánh giá độ sáng của mẫu:

Sử dụng máy so màu quang phổ X-Rite Color i5 theo tiêu chuẩn ISO 105-J01: 1997 tại Trung tâm công nghệ Dệt Ý - Việt trường Đại học Bách Khoa Tp. Hồ Chí Minh để so sánh sự khác biệt về màu sắc giữa các mẫu thí nghiệm. Các giá trị CIE $\mathrm{L} * \mathrm{a} * \mathrm{~b} *$ được đo từ máy đo quang phổ với giá trị $\mathrm{L} *$ hiển thị độ chói trong không gian màu CIELab và các giá trị của nó từ 0 (đen) đến 100 (trắng). Giá trị $+\mathrm{a} *$ biểu thị giá trị màu đỏ và $-\mathrm{a} *$ biểu thị màu xanh lá cây, trong khi giá trị $+\mathrm{b} *$ biểu thị giá trị màu vàng và $-\mathrm{b} *$ biểu thị màu xanh lam.

Phần trăm thay đổi độ sáng $\mathrm{L}$ của mẫu sau khi xử lý so với mẫu ban đầu được tính theo công thức:

L*: Hệ số độ sáng của mẫu tiêu chuẩn

$$
\mathrm{L}(\%)=\frac{\mathrm{DL}^{*}}{\mathrm{~L}^{*}} \times 100(\%)
$$

DL*: Hệ số độ lệch về độ sáng của mẫu sau xử lý so với mẫu tiêu chuẩn.

Đánh giá độ bền màu sau giặt:

Độ bền màu sau giặt thực hiện tại Phân viện Dệt may Tp. Hồ Chí Minh theo tiêu chuẩn ISO 105-C06 A1S2010. Độ bền màu được đánh giá bằng thước xám theo hai tiêu chuẩn là độ phai màu và độ dây màu với 5 cấp: Cấp 1 là xấu nhất và cấp 5 là tốt nhất.

\section{KẾT QUẢ VÀ BÀN LUẬN}

3.1 Đặc trưng cấu trúc bề mặt của vải tơ tằm sau khi xử lý chuội và tẩy trắng bằng ozone.

Hình ảnh chụp bằng kính hiển vi điện tử quét của mẫu vải tơ tằm trước và sau xử lý bằng ozone được trình bày trong hình 2 .
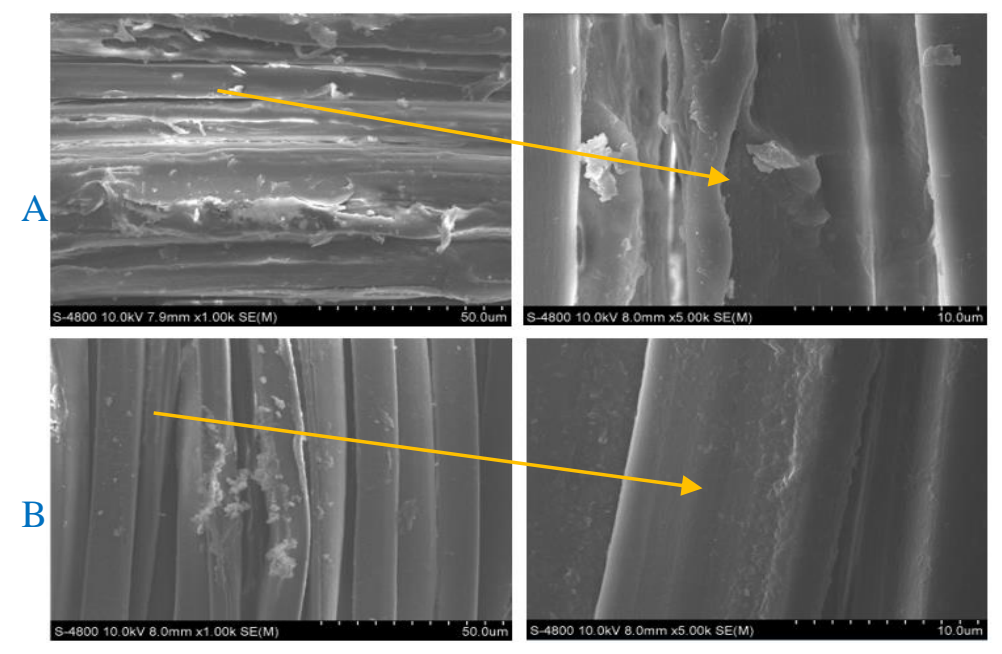

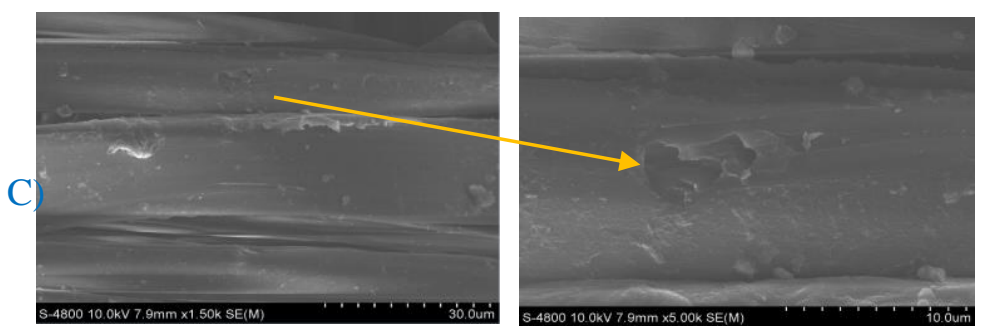

Hình 2. Anh SEM bề mặt vải tơ tằm (A) trước khi chuội và (B) sau khi chuội bằng ozone (mẫu M2), (C) sau khi tẩy trắng ozone (mẫu M4).

Xủ lý chuọi ozone: Quan sát ảnh SEM hình 2A, 2B hầu hết keo sericin trên mẫu vải thô đã được loại bỏ sau khi xử lý chuội bằng ozone. Hàm lượng keo sericin còn lại trên vải bị phân bố rối loạn, không đều trên bề mặt tơ do quá trình chuội không đều ở những vùng các tơ tiếp xúc và ma sát với nhau trên vải. Hình ảnh cũng cho thấy quá trình chuội không gây thiệt hại tới thành phần fibroin của vải tơ tằm.

Xư lý tẩy trắng ozone: Hình $2 \mathrm{C}$ cho thấy có sự phá hủy thành phần fibroin của tơ tạo thành các lõm trên bề mặt fibroin. Vải tơ tằm sau khi chuội bằng xà phòng tiếp tục tẩy trắng bằng ozone đã làm ảnh hưởng đến cấu trúc bề mặt của fibroin, điều này cũng dẫn đến những biến đổi về tính chất cơ lý của vải sau xử lý tẩy trắng ozone được trình bày ở các mục tiếp theo.

\section{2 Đặc trưng cấu trúc hóa học của vải tơ tằm sau khi xử lý chuội bằng ozone.}

Phân tích mẫu M2 bằng quang phổ hồng ngoại FT-IR (Hình 3B) có thể nhận thấy từ biểu đồ tính chất và cường độ của các giải hấp thụ polypeptide ở đỉnh nhọn $1513 \mathrm{~cm}^{-1}$ không hề thay đổi so với trước và sau khi xử lý ozone. Điều này chỉ ra rằng các phân tử protein cơ bản có trong tơ tằm hầu như đều được giữ lại. Tuy nhiên, trong khu vực năng lượng cao hơn mở rộng xung quanh các dao động hóa trị $\mathrm{O}-\mathrm{H}$ và $\mathrm{N}-\mathrm{H}$ của mẫu thô và mẫu xử lý ozone cho thấy việc phá vỡ các peptid và tạo thêm các nhóm amino và cacboxyl tự do. Hơn nữa dải hấp thụ mạnh ở $2450-2350 \mathrm{~cm}^{-1}$ đối với các mẫu đã xử lý cho thấy sự chuyển đổi từ nhóm amide thành các nhóm amino. Do đó có thể thấy rằng việc xử lý ozone tạo ra thêm các nhóm amino trong tơ tằm. Điều này cũng được chứng minh ở một số nghiên cứu trước đây [10].
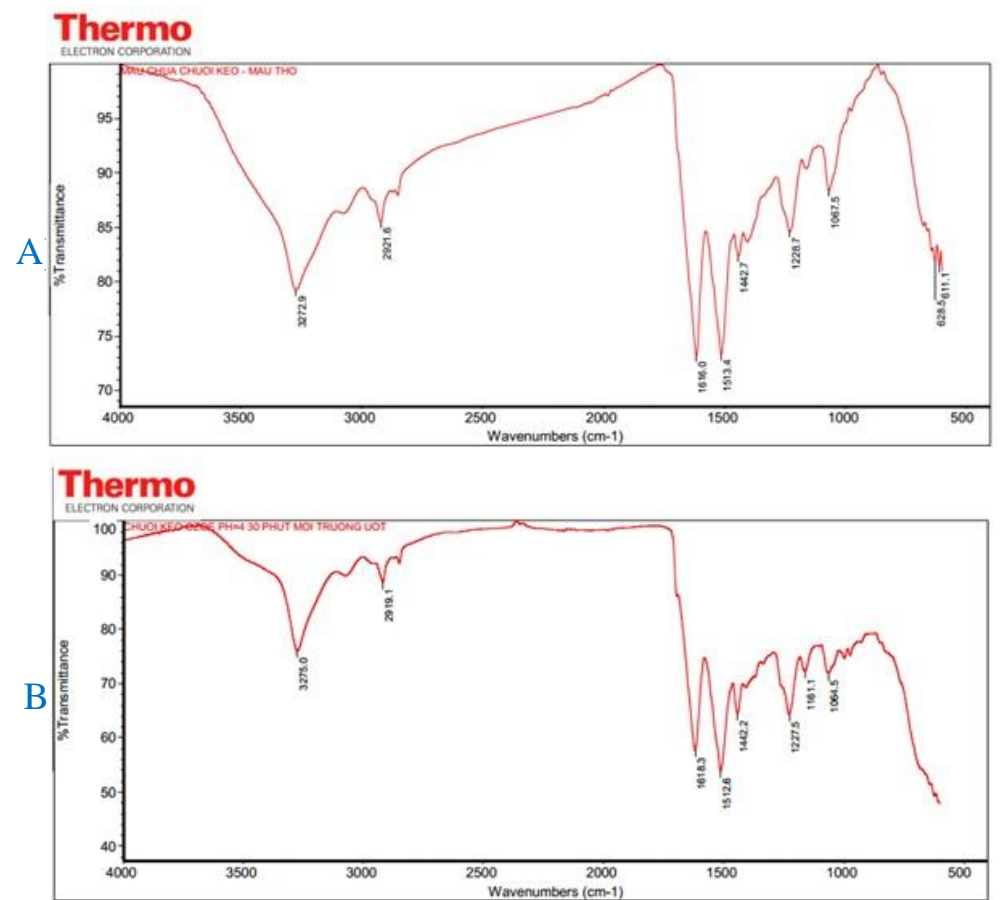

Hình 3. Phổ FT-IR của mẫu vải tơ tằm (A) truớc khi chuội và (B) sau khi chuội ozone trong 30 phút.

\section{3 Đánh giá tính chất cơ lý của vải tơ tằm sau khi xử lý chuội và tẩy trắng bằng ozone}

Quá trình chuội và tẩy trắng làm thay đổi một số tính chất cơ lý của vải tơ tằm. Ảnh hưởng của xử lý ozone lên vải tơ tằm thể hiện ở phần trăm $(\%)$ thay đổi tính chất của vải sau khi chuội và tẩy trắng, được trình bày qua biểu đồ Hình 4. Dấu hiệu (-) và (+) lần lượt biểu thị cho sự giảm và tăng của các tính chất. Mẫu được 
xử lý ozone trong 10, 20 và 30 phút. Kết quả cũng cho thấy yếu tố thời gian xử lý ảnh hưởng đáng kể đến các tính chất của vải sau khi chuội.

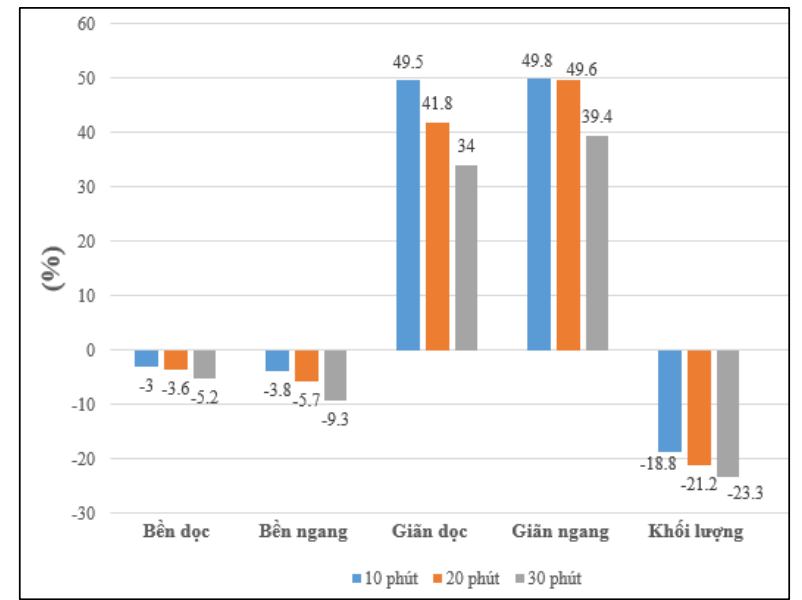

A)

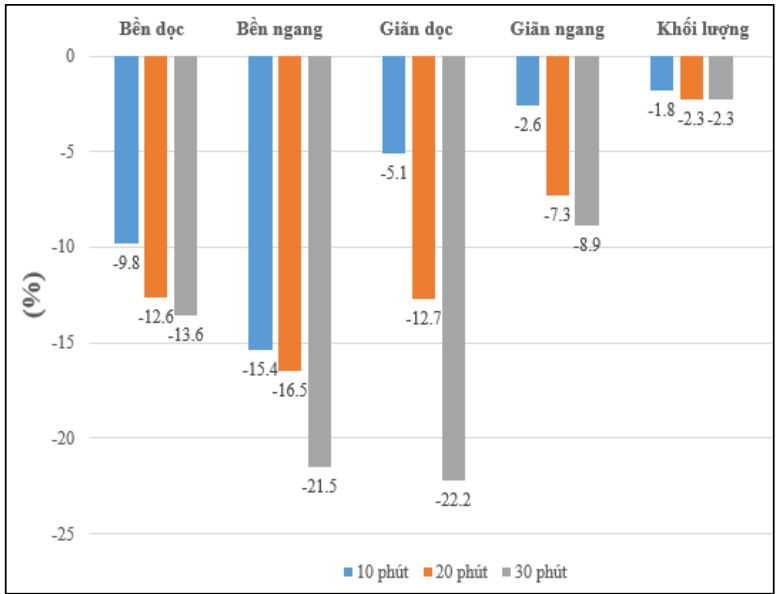

B)

Hình 4. Biểu đồ tính chất co lý của vải (a) Sau khi chuội ozone, (b) Sau khi tẩy trắng ozone.

Xủ lý chuội ozone: Sự thay đổi của một số tính chất sau khi xử lý ozone được trình bày trong hình 4A.

Về khối lượng mẫu, quá trình chuội ozone làm mất đi gần như toàn bộ lượng sericin bao phủ bên ngoài tơ tằm (Hình $4 \mathrm{~A}$ ). Hàm lượng sericin trong tơ tằm dâu chiếm $17-25 \%$, sáp chiếm $0.37 \%$ trọng lượng sericin, carbohydrate chiếm 1,2-1,6\% trọng lượng tơ tằm thô, khối lượng giảm đi của vải sau xử lý chuội bằng ozone là $23,3 \%$, đa phần là do hàm lượng keo sericin đã được loại bỏ. Tác động của ozone làm giảm lượng axit, ester, aldehyde và keton trong carbohydrate và sáp có thể góp phần làm giảm trọng lượng. Việc loại bỏ các sản phẩm khí như ammonia, carbon dioxit và aldehyde được hình thành bởi các sản phẩm trung gian của axit amin trong quá trình xử lý cũng có thể dẫn tới sự giảm khối lượng, kết quả tương tự cũng được kết luận qua một số nghiên cứu trước đó.

Độ bền đứt của vải giảm do sự phá vỡ các peptid và tạo thêm các nhóm amino và cacboxyl tự do mặc dù các phân tử protein cơ bản có trong tơ tằm hầu như đều được giữ lại, đồng thời sự giảm trọng do loại bỏ lớp sericin sau khi xử lý cũng là nguyên nhân làm giảm độ bền đứt của vải theo hướng dọc và ngang lần lượt là 5,2\% và $9,3 \%$ (Hình $4 \mathrm{~A}$ ). Độ giãn đứt của vải tăng theo hướng dọc là $34 \%$ và hướng ngang 39,4\%. Sau khi chuội keo, mẫu đã loại bỏ được hầu hết hàm lượng sericin giúp giải phóng hai sợi fibroin, làm giảm độ cứng và ma sát trên tơ, tơ dễ dàng bị kéo giãn. Ngoài ra độ giãn đứt theo hướng ngang cao hơn độ giãn dứt hướng dọc do cấu trúc vải mẫu có số sợi chập ngang cao hơn số sợi chập dọc.

Xủ lý tẩy trắng ozone: Sự thay đổi một số tính chất của mẫu sau khi tẩy trắng ozone được trình bày trong hình 4B.

Khối lượng của mẫu tơ tằm thô sau khi chuội bằng xà phòng giảm $23.8 \%$ và giảm thêm khoảng từ $1.8-2.3 \%$ khi được tẩy trắng bằng ozone. Quá trình này đã tiếp tục tách bỏ một phần chất màu và lượng nhỏ keo sericin bị tơ hấp thụ lại sau khi bị tách ra ở quá trình chuội keo, đồng thời loại bỏ một số chất chưa được loại bỏ hết ở quá trình chuội. Một số chất được loại bỏ trong quá trình này bao gồm các axit, este, aldehyde và các keton đã được tách ra từ carbohydrat, sáp và một số sản phẩm khí được tạo ra ở giai đoạn trung gian của axit amin như ammoniac, cacbon dioxit.

Tẩy trắng bằng ozone cũng làm giảm độ bền kéo đứt hướng dọc và hướng ngang lần lượt là 13,6\% và 21,5\% (Hình $4 \mathrm{~B}$ ). Phân tích các ảnh SEM (Hình $2 \mathrm{C}$, mục 3.1 ) ta thấy rằng tẩy trẳng bằng ozone làm ảnh hưởng tới thành phần fibroin trên vải, điều này cũng là nguyên nhân làm cho độ bền kéo đứt của vải giảm. Xử lý ozone để tẩy trắng làm giảm độ giãn đứt hướng dọc $22,2 \%$ và hướng ngang $8,9 \%$ (Hình $4 \mathrm{~B}$ ). Sau khi được chuội xà phòng để loại bỏ một lượng lớn keo sericin, vải lại tiếp tục trải qua công đoạn tẩy trắng bằng ozone, khối lượng mẫu tiếp tục giảm đi, quá trình xử lý tẩy trắng đã làm ảnh hưởng tới fibroin trong vải, sự mất đi của ammoniac, cacbon dioxit và aldehyde trong fibroin có thể dẫn tới sự loại bỏ các mạch ngắn ra khỏi đại phân tử tơ tằm làm giảm độ bền và giãn đứt của mẫu. 


\section{4 Đánh giá độ sáng của vải sau khi xử lý chuội và tẩy trắng bằng Ozone}

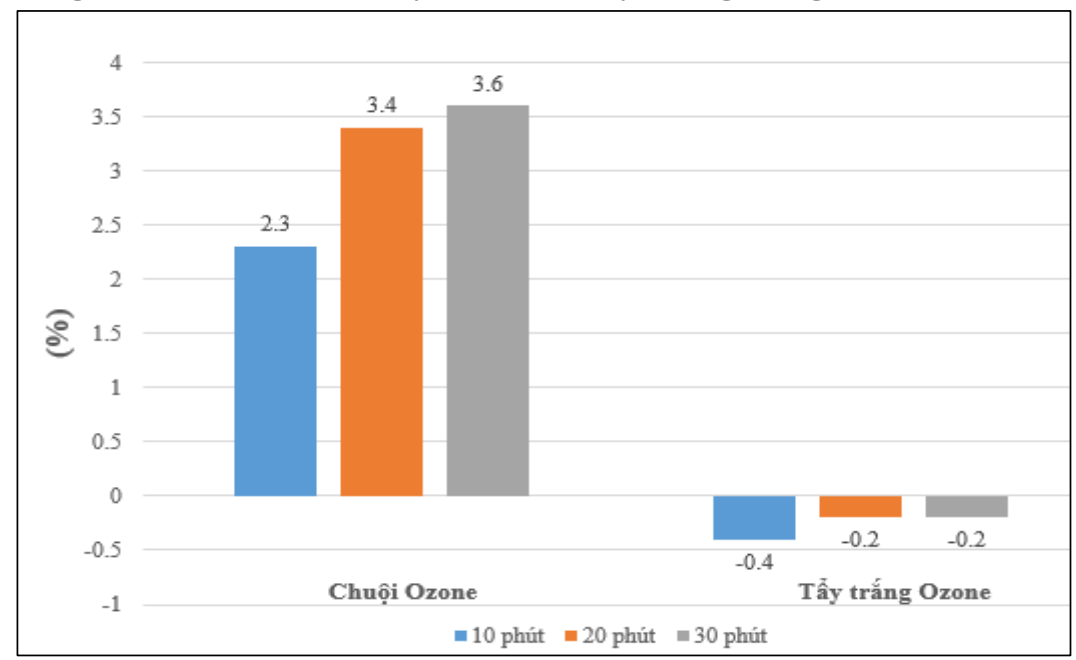

Hình 5. Sụ thay đổi độ sáng của mẫu sau khi chuội keo và tẩy trắng bằng ozone

Kết quả khảo sát Hình 5 cho thấy quá trình xử lý chuội keo bằng ozone đã làm độ sáng của vải tăng. Ngoài fibroin và sericin là những protein tự nhiên, tơ tằm thô còn chứa một số tạp chất hòa tan trong este, rượu etylic và các chất màu thiên nhiên thường có màu vàng. Việc xử lý ozone đã giúp loại bỏ các hàm lượng chất trên và các chất như chất bẩn, dầu, sáp trên vải cũng đã được loại bỏ vì vậy vải tơ tằm sau xử lý ozone trắng sáng hơn so với vải tơ tằm thô.

Mẫu sau khi chuội xà phòng tiếp tục được xử lý tẩy trắng bằng ozone làm độ sáng của mẫu giảm, nguyên nhân có thể do quá trình oxy hóa của hàm lượng amino axit dư đặc biệt là glycine, alanin, serine và tyrosine sau quá trình chuội làm vải ngả vàng.

\subsection{So sánh và đánh giá phương pháp xử lý vải tơ tằm bằng ozone với phương pháp chuội bằng xà phòng và tẩy trắng bằng $\mathrm{H}_{2} \mathrm{O}_{2}$}

Mẫu tơ chuội bằng xà phòng và tẩy trắng bằng $\mathrm{H}_{2} \mathrm{O}_{2}$ được so sánh với mẫu chuội và tẩy trắng bằng ozone trong 30 phút. Dấu hiệu (-) và (+) lần lượt biểu thị cho sự giảm và tăng các tính chất cơ lý của mẫu sau xử lý (Bảng 1).

Bảng 1. Một số tính chất của vải thay đổi sau khi chuội và tẩy trắng bằng hai phuơng pháp.

\begin{tabular}{|l|l|c|c|c|c|}
\hline \multicolumn{2}{|c|}{ Tính chất } & $\begin{array}{c}\text { Chuội xà } \\
\text { phòng }\end{array}$ & Chuội ozone & Tẩy trắng $\mathbf{H}_{2} \mathbf{O}_{2}$ & $\begin{array}{c}\text { Tẩy trắng } \\
\text { ozone }\end{array}$ \\
\hline \multicolumn{2}{|l|}{ Khối lượng $(\%)$} & -23.8 & -23.3 & -3.8 & -2.3 \\
\hline \multirow{2}{*}{ Độ sáng } & 6.0 & 3.6 & 4.2 & -0.2 \\
\hline \multirow{2}{*}{$\begin{array}{l}\text { Độ bền đứt } \\
(\%)\end{array}$} & Hướng dọc & -6.1 & -5.2 & -14.17 & -13.6 \\
\cline { 2 - 6 } & Hướng ngang & -6.5 & -9.3 & -14.23 & -21.5 \\
\hline \multirow{2}{*}{$\begin{array}{l}\text { Độ giãn đứt } \\
(\%)\end{array}$} & Hướng dọc & 12.9 & 34.0 & -12.65 & -22.2 \\
\cline { 2 - 6 } & Hướng ngang & 15.7 & 39.4 & -8.37 & -8.9 \\
\hline
\end{tabular}

Kết quả so sánh (Hình 6A) cho thấy với mục đích chuội keo thì phương pháp ozone mang lại hiệu quả cao hơn so với phương pháp xà phòng. Mẫu sau xử lý bằng ozone có độ giãn đứt dọc tăng $34 \%$, nhiều hơn so với mẫu xử lý bằng xà phòng tăng $12,9 \%$, các tính chất còn lại như khối lượng, độ bền đứt và độ sáng của vải chênh lệch nhau từ $0,5-2,8 \%$. Hơn nữa, phương pháp ozone chỉ sử dụng nồng độ xà phòng $2 \mathrm{~g} / 1$, bằng khoảng $40 \%$ so với phương pháp chuội keo bằng xà phòng là $5 \mathrm{~g} / 1$, thời gian xử lý chuội ozone cũng ít hơn so với chuội xà phòng khoảng 20 phút. 


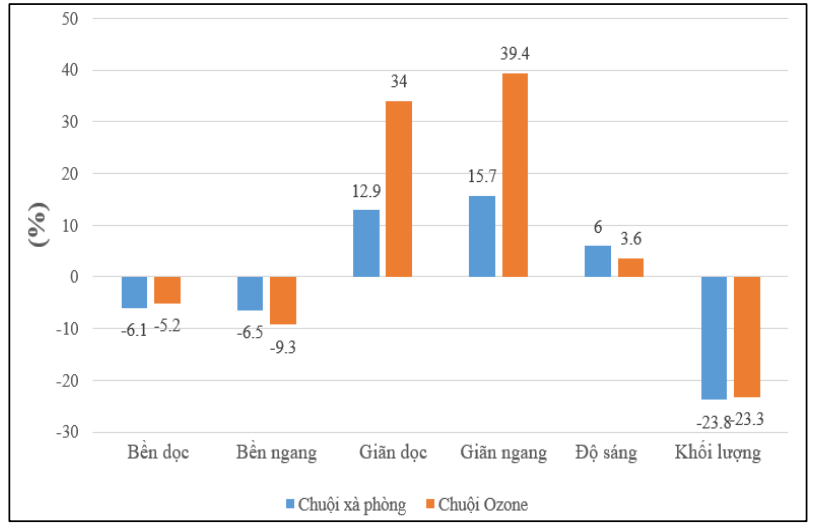

A)

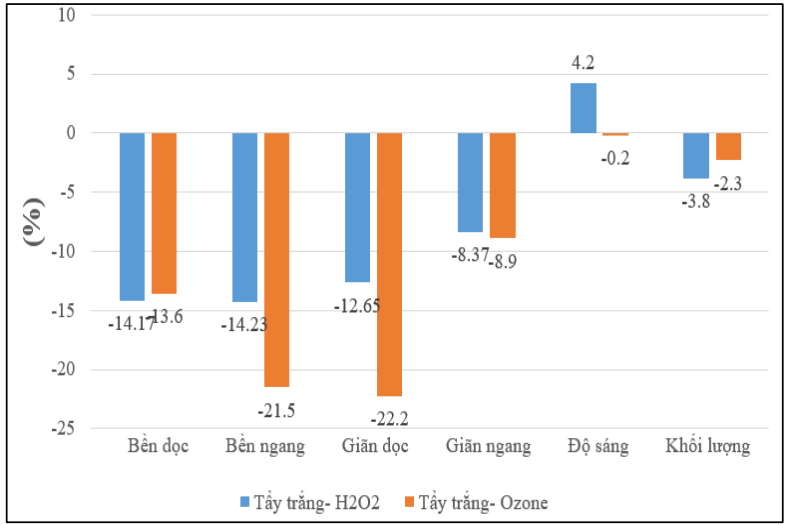

B)

Hình 6. So sánh hai phưong pháp (A) Xủ lý chuọi keo và (B) Xử lý tẩy trắng

Với mục đích thay thế $\mathrm{H}_{2} \mathrm{O}_{2}$ để tẩy trắng cho vải tơ tằm sau khi chuội bằng xà phòng thì phương pháp xử lý ozone chưa mang lại hiệu quả như mong đợi (Hình $6 \mathrm{~B})$. Tẩy trắng bằng ozone làm độ sáng của vải giảm $0,2 \%$ trong khi tẩy trắng bằng $\mathrm{H}_{2} \mathrm{O}_{2}$ theo phương pháp truyền thống giúp độ sáng của mẫu tăng $4,2 \%$, đồng thời các tính chất còn lại như khối lượng, độ bền đứt và độ giãn đứt cũng giảm ít hơn so với mẫu tẩy trắng bằng ozone từ $0,5-7 \%$.

\section{6 Đánh giá độ bền màu vẽ trang trí của mẫu khăn tay sử dụng vải chuội bằng ozone}

Vải tơ tằm thô sau khi xử lý ozone với mục đích chuội keo đã được trang trí theo phương pháp vẽ thủ công bằng màu vẽ lụa chuyên dụng trong thiết kế thời trang ứng dụng làm khăn tay, kết quả thử nghiệm độ bền màu sau giặt của khăn được trình bày trong Bảng 2 . Kết quả cho thấy mẫu có độ bền màu sau giặt tốt, khả năng ứng dụng thành phẩm vải chuội ozone vào thiết kế khăn tay trang trí trong ngành may mặc và thời trang là khả thi.

Bảng 2. Độ bền màu của mẫu khăn tay sử dụng vải chuội bằng Ozone.

\begin{tabular}{|c|c|c|c|c|c|c|c|c|c|c|}
\hline \multirow{2}{*}{$\begin{array}{c}\text { Tính } \\
\text { chất }\end{array}$} & \multicolumn{4}{|c|}{ Phai màu } & \multicolumn{5}{c|}{ Dây màu } \\
\cline { 2 - 21 } & Xanh lá & $\begin{array}{c}\text { Xanh } \\
\text { biển }\end{array}$ & Tím & Trắng & Acetate & Cotton & Nylon & Polyester & Acrylic & Wool \\
\hline Cấp độ & $3-4$ & $3-4$ & $3-4$ & 4 & $4-5$ & 4 & $4-5$ & $4-5$ & $4-5$ \\
\hline
\end{tabular}

\section{KẾT LUẬN}

Phương pháp xử lý ozone có ảnh hưởng đáng kể đến tính chất của vải tơ tằm khi sử dụng với mục đích chuội keo hoặc tẩy trắng vải tơ tằm sau khi chuội xà phòng, tuy nhiên mức độ ảnh hưởng không giống nhau, thời gian xử lý cũng ảnh hưởng đáng kể đến tính chất vải sau xử lý.

Khảo sát và so sánh giữa hai phương pháp chuội thấy rằng chuội vải mộc bằng ozone mang lại hiệu quả tốt hơn so với phương pháp chuội xà phòng. Mẫu sau xử lý bằng ozone có độ giãn đứt tăng cao hơn mẫu xử lý bằng xà phòng khoảng $24 \%$, các tính chất còn lại như khối lượng, độ bền đứt ngang, độ sáng lần lượt thấp hơn $0.5 \%, 2.8 \%$ và $2.4 \%$. Ozone có thể sản xuất dùng ngay tại chố, quy trình công nghệ xử lý giảm khoảng $40 \%$ lượng xà phòng sử dụng so với phương pháp truyền thống. Có thể thấy khả năng ứng dụng ozone để chuội vải tơ tằm thay cho phương pháp chuội xà phòng truyền thống là hoàn toàn khả thi và cần nghiên cứu thêm để áp dụng với quy mô lớn.

So với phương pháp tẩy trắng thông thường dùng $\mathrm{H}_{2} \mathrm{O}_{2}$, phương pháp tẩy trắng bằng ozone còn gặp một số hạn chế như làm giảm $0,2 \%$ độ sáng của mẫu, độ bền kéo đứt và độ giãn dứt giảm nhiều hơn so với tẩy trắng bằng $\mathrm{H}_{2} \mathrm{O}_{2}$ từ $7-10 \%$. Vì vậy trong nghiên cứu này ozone được đánh giá là không phù hợp để thay thế $\mathrm{H}_{2} \mathrm{O}_{2}$ trong xử lý tẩy trắng vì không đáp ứng được mục đích tăng độ sáng cho vải sau xử lý.

Hướng nghiên cứ tiếp theo của đề tài sẽ tiếp tục đánh giá khả năng xử lý ozone một lần để thay thế cả hai bước chuội và tẩy trắng truyên thống bằng cách thay đổi các thông số công nghệ như môi trường xử lý, độ pH của dung dịch ngấm ép, độ ngấm ép hoặc tăng thời gian xử lý. Kết quả nghiên cứu này là cơ sở cho các 
nhà công nghệ và thiết kế có thể tham khảo và lựa chọn phương pháp xử lý vải tơ tằm nhằm nâng cao chất lượng sản phẩm dệt, xây dựng quy trình sản xuất tiết kiệm tài nguyên và thân thiện hơn với môi trường.

\section{LÒ̀I CẢM ƠN}

Nhóm tác giả xin cảm ơn sự hỗ trợ kinh phí từ Trường Đại học Công nghiệp Tp. Hồ Chí Minh thông qua đề tài Nghiên cứu khoa học và phát triển Công nghệ số $35-\mathrm{HĐ} / \mathrm{DHCN}$. Đồng thời cảm ơn các thầy cô Bộ môn Kỹ thuật Dệt may - Khoa Cơ khí Trường Đại học Bách Khoa Tp. Hồ Chí Minh, Phân viện Dệt may Tp. Hồ Chí Minh, Trung tâm Công nghệ sinh học Tp. Hồ Chí Minh đã hỗ trợ để chúng tôi hoàn thành nghiên cứu này.

\section{TÀI LIẸU THAM KHẢO}

[1] Freddi G., Mossotti R., Innocenti R., , Degumming of silk fabric with several proteases, Journal of Biotechnology, 2003. 106 (1), p. 101-112,

[2 M. Clark, Handbook of textile and industrial dyeing, Woodhead Publishing Series in Textile, 2011. 116 (1).

[3] J. Staehelin N. R. P. Harris, C. Appenzeller J. Eberhard, Richard Elliot Benedick, Ozone trends: A review, Reveiws of Giophysics, Advancing Earth and space science, Ozone diplomacy, 2001, 39 (2), p.231-290

[4] Myung Sun Lee Muncheul Lee Tomiji Wakida Masumi Saito Takumi Yamashiro Kenji Nishi Goichi Inoue Shinzo Ishida, Ozone-gas treatment of cationic dyeable polyester and poly (butylene terephthalate) fibers, Journal of applied Polymer, 2007. 104 (4), p. 2423-2429.

[5] Kerim Duran, Aysegul E. Korlu, Ibrahim M. Bahtiyari, Seher D. Perincek, An Investigation in the Use of Ozone Gas in the Bleaching of Cotton Fabrics, The Journal of the International Ozone Association, 2007. 29 (5), p. 325333.

[6] M.L. Gulrajani, Degumming of silk, Coloration Technology, 1992. 22 (1), p. 79-89.

[7] Nursah Balci, Zeynep Omerogullari, Dilek Kut, Huseyin Aksel Eren, Effects of plasma and ozone treatments on tensile and whiteness properties of $100 \%$ silk, Journal of The Faculty of Engineering, 2015. 20 (2): p. 43-56.

[8] D. Sargunamani, N. Selvakumar, Comparative analysis of the effect of ozone treatment on the properties of mulberry and tassar silk fabrics, The Journal of The Textile Institute, 2011. 102 (10): p. 870-874

[9] Tomiji Wakida, Muncheul Lee, Jeong Hun Jeon, Takako Tokuyama, Hiroshige Kuriyama, Shinzo Ishida, OzoneGas Treatment of Wool and Silk Fabrics, J-starge, 2004. 60 (7): p. 213-219

[10] D. Sargunamani, N. Selvakumar, A study on the effects of ozone treatment on the properties of raw and degummed mulberry silk fabrics, Polymer Degradation and Stability, 2006. 91 (11): p. 2644-2653

Ngày nhận bài:22/06/2020

Ngày chấp nhận đăng: 01/04/2021 